\title{
CARBOCHAIN POLYMER-GLUCOSE HYBRIDS: SYNTHESIS, THERMAL/MECHANICAL PROPERTIES AND BIODEGRADABILITY
}

\author{
VLADIMIR BERSHTEIN ${ }^{1}$, PAVEL YAKUSHEV ${ }^{1}$, IZABELA \\ BUKOWSKA-ŚLUZ ${ }^{2}$, MAGDALENA SOBIESIAK ${ }^{2}$ \\ and BARBARA GAWDZIK ${ }^{2}$ \\ ${ }^{1}$ Ioffe Institute \\ 26 Politekhnicheskaya str. \\ 194021 St.-Petersburg \\ Russia \\ e-mail: vbersht.polmater@mail.ioffe.ru \\ ${ }^{2}$ Faculty of Chemistry \\ Maria Curie-Sklodowska University \\ Pl. Marii Curie-Sklodowskiej 3 \\ 20-031 Lublin \\ Poland
}

\begin{abstract}
Novel monomers, combining synthetic and natural compounds, methacrylated glucose (MGlu) and acrylated glucose (AGlu), and their polymers and hybrid copolymers with methyl methacrylate (MMA) or MMA/N-vinylpyrrolidone (MMA/NVP, 1:1), at 10, 20 or 30wt.\% MGlu or AGlu, were synthesized. These polymeric materials were characterized over the broad temperature range by DMA and TGA, and also in the biodegradation tests. Constrained dynamics effect and more pronounced dynamic heterogeneity over the broad temperature range, with increasing $T_{\mathrm{g}}$ values by $\sim 15^{\circ} \mathrm{C}-30^{\circ} \mathrm{C}$, were registered in all cases in
\end{abstract}

Keywords and phrases: synthetic polymer-glucose hybrids, mechanical and thermal properties, biodegradability.

Received December 5, 2017

(C) 2018 Scientific Advances Publishers 
the hybrids compared to those in the initial polymers. Some increase in the thermal stability at $\sim 150^{\circ} \mathrm{C}-240^{\circ} \mathrm{C}$ was attained in some of the hybrids. A considerable rise of modulus and essential enhancing of biodegradability were also registered but only under conditions of elevated polymer hygroscopicity, i.e., for MMA/NVP copolymer.

\section{Introduction}

Monosaccharides (glucose and others), oligosaccharides and polysaccharides (cellulose, starch), are the most abundant class of organic compounds found in living organisms and synthesized by plants via photosynthesis processes. Now these carbohydrates and their processing products are used in different areas of industry, frequently in combination with synthetic polymers to enhance biodegradability and biocompatibility of the latter ones. Thus, starch-synthetic polymer blends and derivatives are known, which sometimes provide the complete biodegradability [1, 2]. Therefore, they are often used for the manufacture of plastic packaging; using only synthetic materials contributes to increasing the amount of plastic waste, which causes serious environmental and economic problems. The best solution of the above problem is to produce materials with biodegradable components, in particular including some additives of carbohydrates [3-6].

On this way, it would be of interest also to search for new saccharidecontaining monomers capable of creating in the process of copolymerization with another monomers new hybrid polymeric materials degradable in the environment. This problem is especially topical for non-biodegradable or slightly degradable synthetic polymers. There are some attempts on this way. For example, the products based on acrylic/methacrylic derivatives and cellulose, with increased biodegradability and water absorption, were prepared for biomedical applications [6]. New methacrylate hydrogels were described which combined saccharide moieties and methacrylate groups [7]. Monosaccharide-functionalized poly(phenyl acetylene)s and their composites with multi-walled carbon nanotubes (MWCNTs) were synthesized [8]. The results [9] suggest that 
such functionalized poly (phenyl acetylene)s can be promising candidates for the fabrication of tissue-engineering materials. Glucose-functionalized MWCNTs provided a fine dispersion of MWCNT bundles in the polymer matrix and significantly increased the thermal stability of hybrid bionanocomposites obtained [10]. Recently, we presented the preliminary experimental data on methacrylated monosaccharides as the modifiers for carbochain polymers [11].

The goal of this work was the attempt of enhancing properties and biodegradability of carbochain linear polymers via their chemical hybridization with glucose. For this aim, the new products, methacrylated and acrylated derivatives of glucose, and their copolymers with methyl methacrylate (MMA) or MMA/N-vinylpyrrolidone mixture (MMA/NVP), were synthesized and characterized.

\section{Experimental Part}

\subsection{Materials}

The materials for investigation were prepared in three stages. First, 2,3,4,6-tetra-O-acetate- $\mathrm{D}$-glucopyranose bromide was obtained by the procedure described by Vogel [12]. Then, the reaction of the product obtained with potassium methacrylate or potassium acrylate in dimethyl formamide was performed with formation of 2,3,4,6-penta-O-acetate-1methacryloylglucopyranose (MGlu) or 2,3,4,6-penta-O-acetate-1-acryloylglucopyranose (AGlu), respectively. And, thirdly, these modifiers were incorporated into carbochain polymers by copolymerization, with formation the hybrid copolymer materials.

Thus, the new products, methacrylated derivative of glucose, acrylated derivative of glucose, their polymers and copolymers with MMA and MMA/NVP mixture were synthesized and characterized. 


\subsubsection{Reagents}

Glucose, phosphorus (red, amorphous), methacrylic acid, acrylic acid, and N,N-dimethylformamide came from Fluka AG (Buchs, Switzerland). Reagent grade acetic anhydride, anhydrous zinc chloride, bromine, potassium hydroxide, hexane, methanol, dichloromethane, and sodium bicarbonate were received from POCh (Gliwice, Poland). Methyl methacrylate (MMA) and N-vinylpyrrolidone (NVP) came from SigmaAldrich. Photoinitiator Irgacure 651 was bought in Ciba (Basel, Switzerland).

\subsubsection{Preparation of 2,3,4,6-tetra-O-acetate-D-glucopyranose bromide}

To obtain bromide of 2,3,4,6-tetra-O-acetate- $\mathrm{D}$-glucopyranose, the procedure described by Vogel [12] was applied. According to this procedure, $200 \mathrm{~mL}$ of acetic anhydride and $8 \mathrm{~g}$ of anhydrous zinc chloride were placed into a three-necked flask and stirred till zinc chloride will be dissolved. Next, $50 \mathrm{~g}$ of glucose was added while stirring, and the mixture was heated for $1 \mathrm{~h}$ at $30^{\circ} \mathrm{C}$. When the reaction was over, the mixture was cooled to $20^{\circ} \mathrm{C}$, and $15.5 \mathrm{~g}$ of phosphorus was added while stirring. Next, $29 \mathrm{ml}$ of bromine was dropped while stirring. After adding bromine, $18 \mathrm{~mL}$ of water was added and the mixture was maintained at room temperature for $24 \mathrm{~h}$. Then, it was diluted by $150 \mathrm{~mL}$ of dichloromethane and filtered through a glass funnel. After that, the organic layer was transferred to the distributor and washed with two portions of ice water. Next, the organic layer (in dichloromethane) was introduced while stirring into a saturated sodium bicarbonate solution containing a bit of crushed ice. When carbon dioxide ceased to exude, organic layer was dried over silica gel, and the solvent was removed on a rotary evaporator at $60^{\circ} \mathrm{C}$. The obtained precipitate of 2,3,4,6-tetra-O-acetate-Dglucopyranose bromide was dried in air. After crystallization from hexane its m.p. was $88^{\circ} \mathrm{C}-89^{\circ} \mathrm{C}$. 
2.1.3. Preparation of 2,3,4,6-penta-O-acetate-1-methacryloylglucopyranose (MGlu) and 2,3,4,6-penta-O-acetate-1-acryloylglucopyranose (AGlu)

To obtain MGlu, 8g of 2,3,4,6-tetra-O-acetate-D-glucopyranose bromide, $7.4 \mathrm{~g}$ of methacrylic acid, $5.5 \mathrm{~g}$ potassium hydroxide, and $32 \mathrm{~mL}$ of $\mathrm{N}, \mathrm{N}$-dimethylformamide were placed into a flask and heated to $65^{\circ} \mathrm{C}$ while stirring; heating continued for $30 \mathrm{~min}$. When the reaction was over, the resulting mixture was poured into water containing crushed ice, stirring constantly. Next, the obtained MGlu precipitate was filtered off, dried in air and crystallized from methanol. Its m.p. was $97.8^{\circ} \mathrm{C}-98.1^{\circ} \mathrm{C}$. The similar procedure (with using acrylic acid) was applied for preparing 2,3,4,6-penta-O-acetate-1-acryloylglucopyranose (AGlu) with m.p. $102.6^{\circ} \mathrm{C}$ $103.0^{\circ} \mathrm{C}$.

Figure 1 shows a scheme of synthesis of MGlu and the AGlu formula. The chemical structures of the products obtained were confirmed by

${ }^{1} \mathrm{H}$ NMR, ${ }^{13} \mathrm{C}$ NMR, and FTIR analyses. 


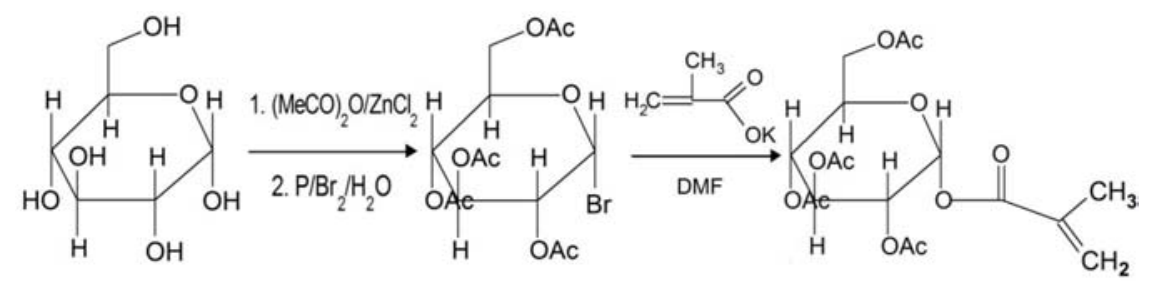

(a)

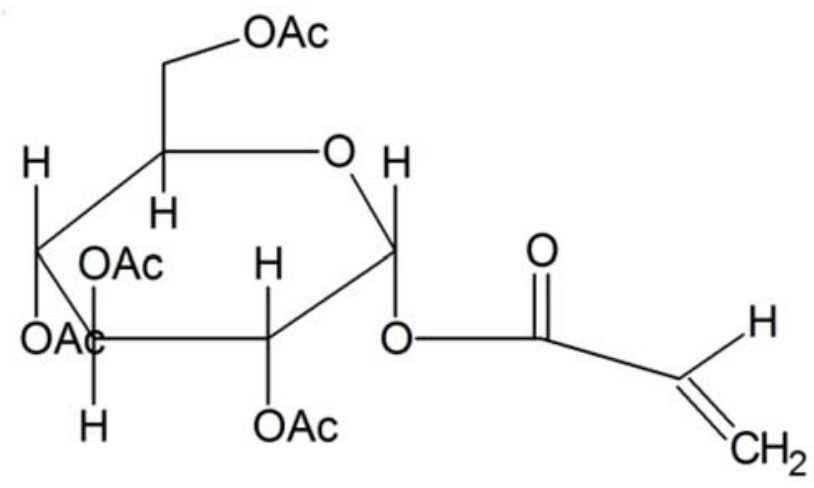

(b)

Figure 1. (a) A scheme of synthesis and chemical structure of 2,3,4,6penta-O-acetate-1-methacryloylglucopyranose, (b) the structural formula of 2,3,4,6-penta-O-acetate-1-acryloylglucopyranose.

\subsubsection{Preparation of polymeric samples}

In order to prepare the polymeric materials under study, MMA or MMA/NVP (1:1) mixture were mixed with 10, 20 or 30wt.\% MGlu or AGlu. Next, 1wt.\% of UV photoinitiator (Irgacure 651) was introduced into the monomers, and the photopolymerization for $3 \mathrm{~h}$ at $20^{\circ} \mathrm{C}$ was performed by using black light lamp 366nm (Philips, TSM0022 TL-D18W). As the reference materials, homopolymers of MMA, MGlu, AGlu and MMA/NVP copolymer were also prepared via the same procedure. It should be noted that all the hybrids are linear polymer systems since they manifested solubility in usual solvents. All plates obtained were of $1.5 \mathrm{~mm}-2 \mathrm{~mm}$ in thickness. 


\subsection{Methods}

Dynamic mechanical analysis (DMA) and thermogravimetric analysis (TGA) were used for the characterization of samples, and also their comparative biodegradability was estimated.

DMA was performed in the tensile mode using a DMS 6100 Seiko Instruments spectrometer, at $0.1,1$, and $10 \mathrm{~Hz}$ over the temperature range from $-120^{\circ} \mathrm{C}$ to $130^{\circ} \mathrm{C}$, at heating rate of $2^{\circ} \mathrm{C} \mathrm{min}{ }^{-1}$. Loss modulus $E^{\prime \prime}$, storage (dynamic) modulus $E^{\prime}$, and mechanical loss factor tan $\delta=E^{\prime \prime} / E^{\prime}$ as the functions of temperature were measured. The test samples were of about $40 \times 10 \times 1.5 \mathrm{~mm}^{3}$ in size. Glass transition temperatures, $T_{\mathrm{g}} s$, were determined in the maxima of main relaxation $\tan \delta(T)$ peaks measured at $1 \mathrm{~Hz}$. Moreover, the relevant activation energies of $\alpha$ (glass) transition, $Q_{\alpha}$, and $\beta$ relaxation, $Q_{\beta}$, were estimated from the DMA data obtained at different frequencies.

TGA was carried out using STA 449 F1 Jupiter ${ }^{\circledR}$ (NETZSCH) instrument over the $20^{\circ} \mathrm{C}$ to $500^{\circ} \mathrm{C}$ range, at heating rate of $10^{\circ} \mathrm{C} \mathrm{min}^{-1}$.

Biodegradability tests were performed for three specimens with $60 \times 30 \times 2 \mathrm{~mm}^{3}$ in size for an each composition. The samples were buried into the biologically active soil, free of impurities and particles, at the depth of ca. $20 \mathrm{~mm}$. The soil was maintained at $\mathrm{pH}=5-7$, temperature of $22 \pm 2^{\circ} \mathrm{C}$ and relative air humidity of $20 \pm 2 \%$. The specimens were extracted out every 30 days during overall testing time of 180 days, cleaned, dried in vacuum at $50^{\circ} \mathrm{C}$ for $5 \mathrm{~h}$, and then $24 \mathrm{~h}$ in a dessicator to ensure water desorption before measurements; then, mass loss was estimated. All measurements have been performed in air atmosphere. 


\section{Results and Discussion}

\subsection{Dynamic mechanical analysis}

The results of comparative dynamic mechanical analysis of PMMA, MMA/NVP copolymer and a series of hybrids, based thereon and MGlu and AGlu, are presented in Figures 2-7 and in Table 1. On the whole, embedding MGlu or AGlu units into polymer chains results in the considerable changes in polymer relaxation and elastic properties.

Figure 2 displays loss modulus $E^{\prime \prime}$ versus temperature plots obtained for neat PMMA and its hybrids with MGlu units over the temperature range of about $250^{\circ} \mathrm{C} . T_{\mathrm{g}}, Q_{\alpha}$ and $E_{20^{\circ}}$ values for these samples are presented in Table 1. One can see two peculiarities of the relaxation spectra of the hybrids: (a) an essential suppression of mobility ("constrained dynamics effect") over the whole temperature range under study, with shifting $T_{\mathrm{g}}$ from $108^{\circ} \mathrm{C}$ to $124^{\circ} \mathrm{C}$ (Table 1), and (b) the distinctive manifestation of the complicated nature of the broad $\beta$-relaxation region, extending from $-50^{\circ} \mathrm{C}$ to $50^{\circ} \mathrm{C}$. The latter has the maximum only at $10^{\circ} \mathrm{C}-20^{\circ} \mathrm{C}$ for neat PMMA but the contour with, e.g., four maxima at $30^{\circ} \mathrm{C}, 0^{\circ} \mathrm{C}, 10^{\circ} \mathrm{C}$, and $35^{\circ} \mathrm{C}$ for the hybrid with $30 \mathrm{wt} . \%$ MGlu (Figure 2). This enhanced dynamic heterogeneity in the $\beta$ relaxation range (this relaxation is associated with noncooperative motion of segments in the points of loosened molecular packing $[13,14]$ ) may be caused, obviously, with the enhanced differences in molecular packing in hybrids containing PMMA and embedded MGlu units. Table 1 shows that dynamic modulus $E^{\prime}$ at $20^{\circ} \mathrm{C}$, i.e., in the region of $\beta$ relaxation, decreases from $3.1 \mathrm{GPa}$ to

\section{5-2.0GPa in these cases.}


Table 1. Glass transition temperatures and activation energies, and storage (dynamic) modulus values obtained by DMA for the materials under study

\begin{tabular}{|c|c|c|c|}
\hline$m$ & $T_{\mathrm{g}}$ & $Q_{\alpha}$ & $E_{20^{\circ}}{ }^{\circ}$ \\
\hline wt. $\%$ & ${ }^{\circ} \mathrm{C}$ & $\mathrm{kJ} / \mathrm{mole}$ & $\mathrm{GPa}$ \\
\hline \multicolumn{4}{|c|}{ PMMA + mMGlu } \\
\hline 0 & 108 & 500 & 3.1 \\
\hline 10 & 116 & 590 & 1.7 \\
\hline 20 & 114 & 660 & 1.5 \\
\hline 30 & 124 & 500 & 2.0 \\
\hline MMA/NVP copolymer + mMGlu \\
\hline 0 & 97 & 350 & 1.3 \\
\hline 10 & 117 & 350 & 1.9 \\
\hline 20 & 115 & 460 & 1.7 \\
\hline 30 & 126 & 410 & 2.0 \\
\hline \multicolumn{4}{|c|}{ MMA/NVP copolymer + mAGlu } \\
\hline 0 & 97 & 350 & 1.3 \\
\hline 10 & 99 & 320 & 1.9 \\
\hline 20 & 108 & 360 & 1.9 \\
\hline 30 & 111 & 380 & 1.8 \\
\hline \multicolumn{4}{|c|}{50} \\
\hline
\end{tabular}

Note: The accuracies of $T_{\mathrm{g}}, Q_{\alpha}$ and $E_{20^{\prime}}$. determinations are $\pm 1^{\circ} \mathrm{C}, \pm 15 \%$ and $\pm 5 \%$, respectively 


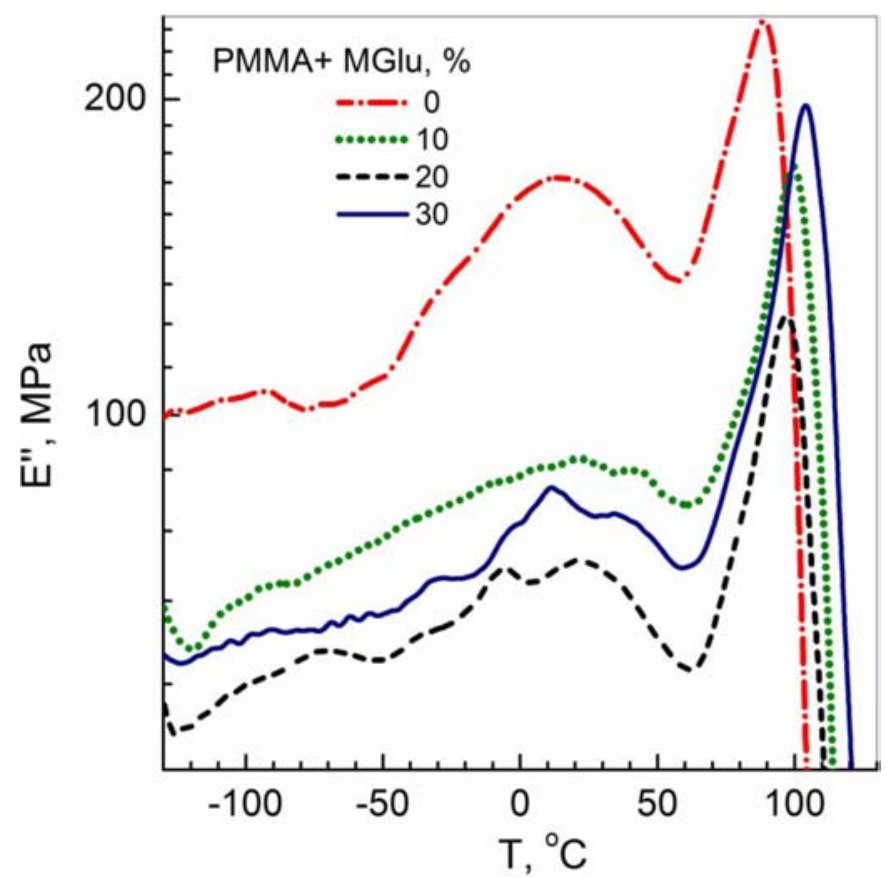

Figure 2. DMA (1Hz): loss modulus $E^{\prime \prime}$ versus temperature dependencies obtained for PMMA and the hybrids (copolymers) of MMA with 10, 20, and 30wt.\% MGlu.

Figures 3-5 and Table 1 present the experimental data on relaxation and elastic properties of neat MMA/NVP copolymer and its hybrids with MGlu or AGlu units. The stronger constrained dynamics effect is observed over the broad temperature range in the copolymer-MGlu hybrids: $T_{\mathrm{g}}$ increases from $97^{\circ} \mathrm{C}$ up to $126^{\circ} \mathrm{C}$ but up to $111^{\circ} \mathrm{C}$ in the case of modifying copolymer with AGlu (Table 1). Figure 3(a) shows that a steep rise of $\tan \delta$ starts at about $60^{\circ} \mathrm{C}$ for neat MMA/NVP copolymer but from $95^{\circ} \mathrm{C}-100^{\circ} \mathrm{C}$ only after embedding $30 \mathrm{wt} . \%$ MGlu into this copolymer. Several discernable sub- $T_{\mathrm{g}}$ relaxations may be seen also in these hybrids' spectra over the temperature range from $-30^{\circ} \mathrm{C}$ to $40^{\circ} \mathrm{C}$ (Figure 3(b)). Again, the discrete character of these spectra implies arising the essential dynamic heterogeneity in the hybrids as a consequence of 
manifestation of $\beta$ relaxation and relaxations with reduced degrees of intermolecular cooperativity of segmental motion at $T<T_{\mathrm{g}}$, due to loosening locally the molecular packing.
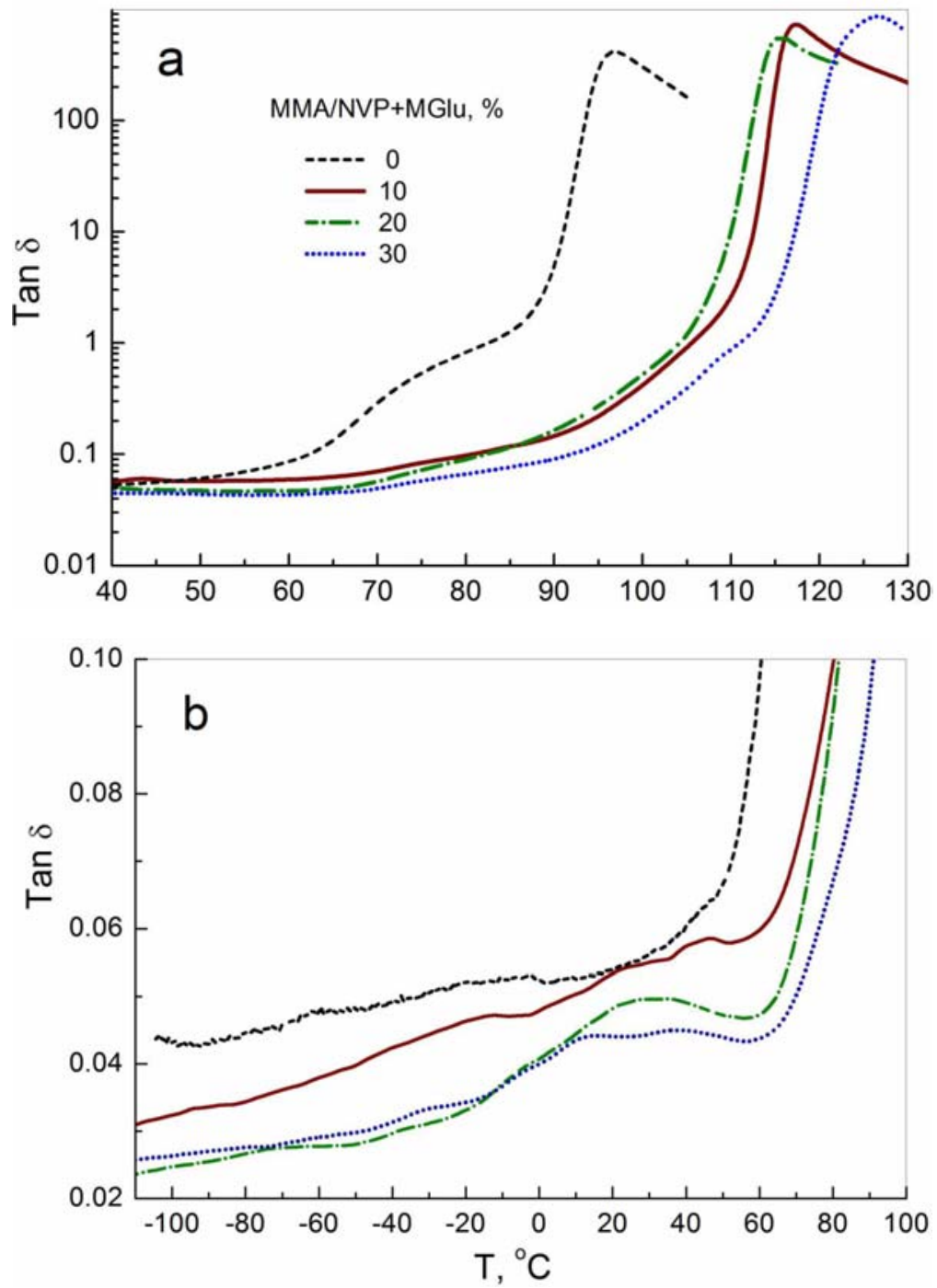

Figure 3. (a), (b) DMA (1Hz): mechanical loss factor tan $\delta$ versus temperature dependencies obtained for MMA/NVP copolymer and its hybrids with 10, 20, and 30wt.\% MGlu. 
MMA/NVP copolymer is characterized with relatively low modulus $E^{\prime}=1.3 \mathrm{GPa}$ at $20^{\circ} \mathrm{C}$, and it increases up to $1.9-2.0 \mathrm{GPa}$ in the hybrids (Table 1). Figures 4(a) and 5(b) show that the enhanced rigidity of the latter hybrids as compared to that of neat copolymer is retained also at elevated temperatures.
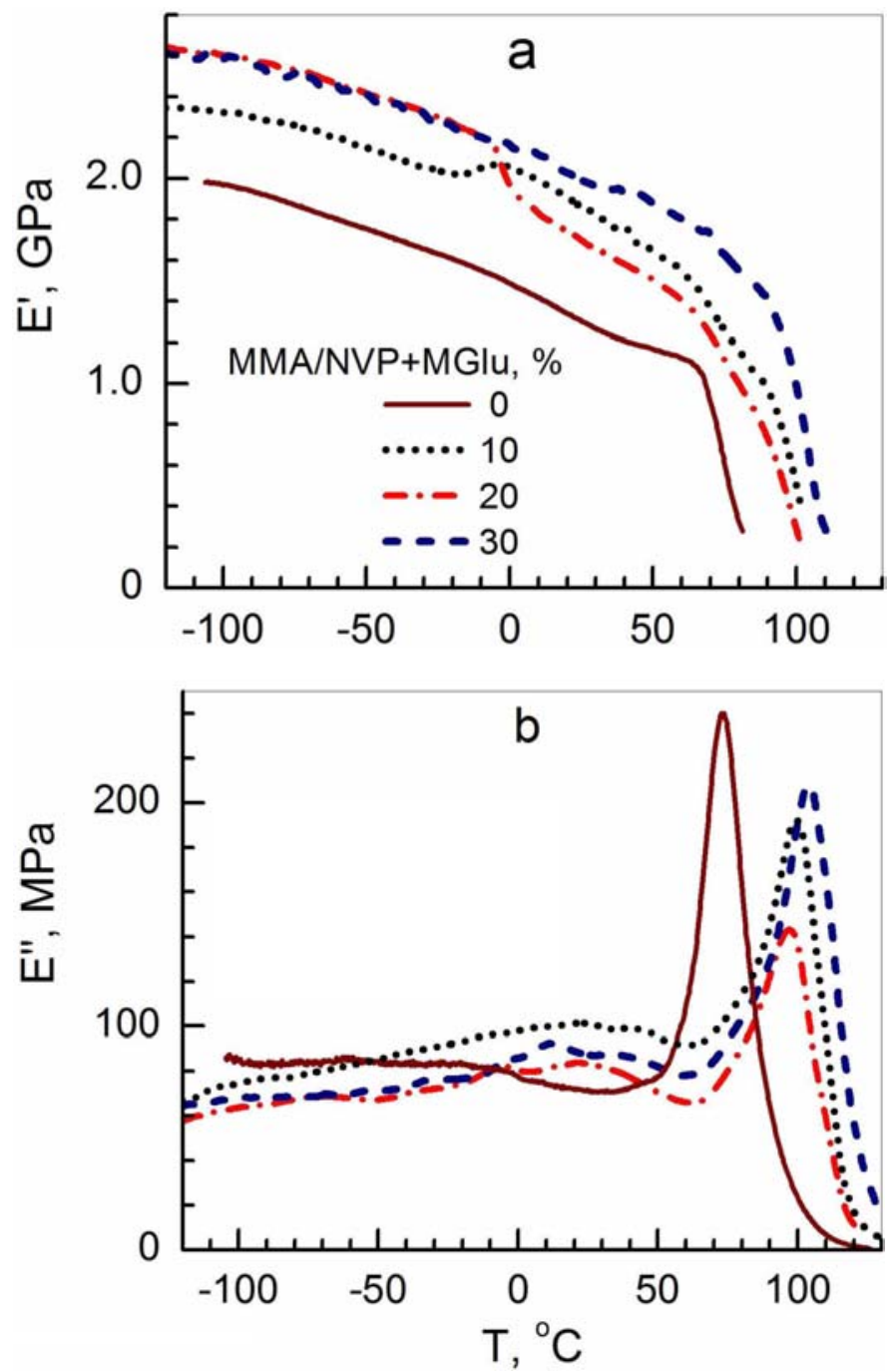

Figure 4. DMA (1Hz): (a) storage (dynamic) modulus $E^{\prime}$, and (b) loss modulus $E^{\prime \prime}$ versus temperature dependencies obtained for MMA/NVP copolymer and its hybrids with 10, 20, and 30wt.\% MGlu. 

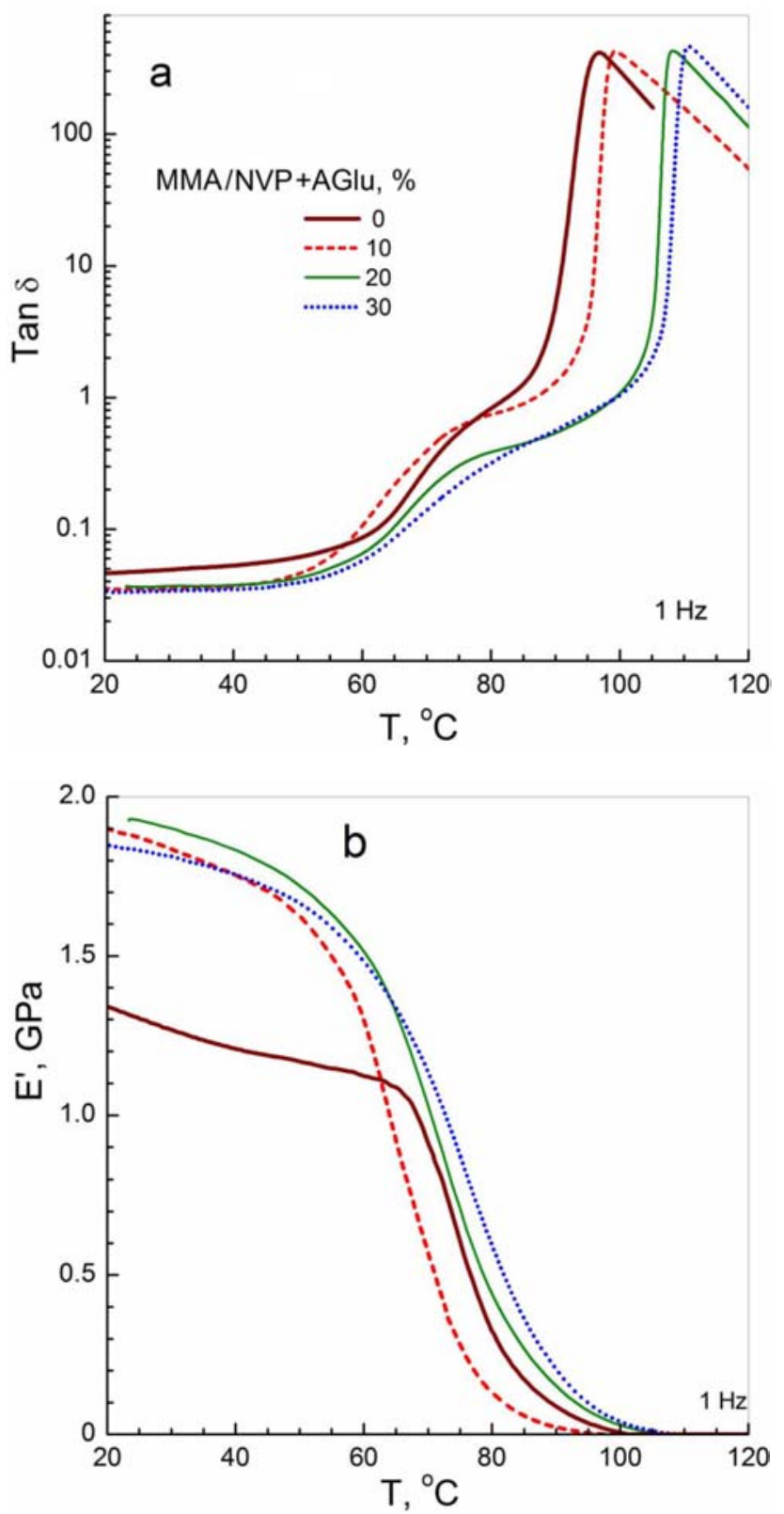

Figure 5. DMA (1Hz): (a) mechanical loss factor tan $\delta$, and (b) storage (dynamic) modulus $E^{\prime}$ versus temperature dependencies obtained for MMA/NVP copolymer and its hybrids with 10, 20, and 30wt.\% AGlu. 
At last, the constrained dynamics effect, caused by covalent embedding glucose derivative, MGlu or AGlu units, into carbon-carbon polymer chains, manifested itself also in the experiments performed at different frequencies (see the examples of the spectra in Figures 6 and 7), with estimating effective activation energies of glass transition $Q_{\alpha}$ and $\beta$ relaxation $Q_{\beta}$. The data presented in Figure 6 show the effect of twice increase in $Q_{\beta}$ value, from 60 to $120 \mathrm{~kJ} / \mathrm{mole}$, in the PMMA/MGlu (20\%) hybrid. Increasing $T_{\mathrm{g}}$ of polymers under study due to their modification was accompanied also with increasing $Q_{\alpha}$ by $10-30 \%$, for example, from 500 to $590-660 \mathrm{~kJ} / \mathrm{mole}$ for the hybrids of PMMA with 10-20wt.\% MGlu (Table 1). 

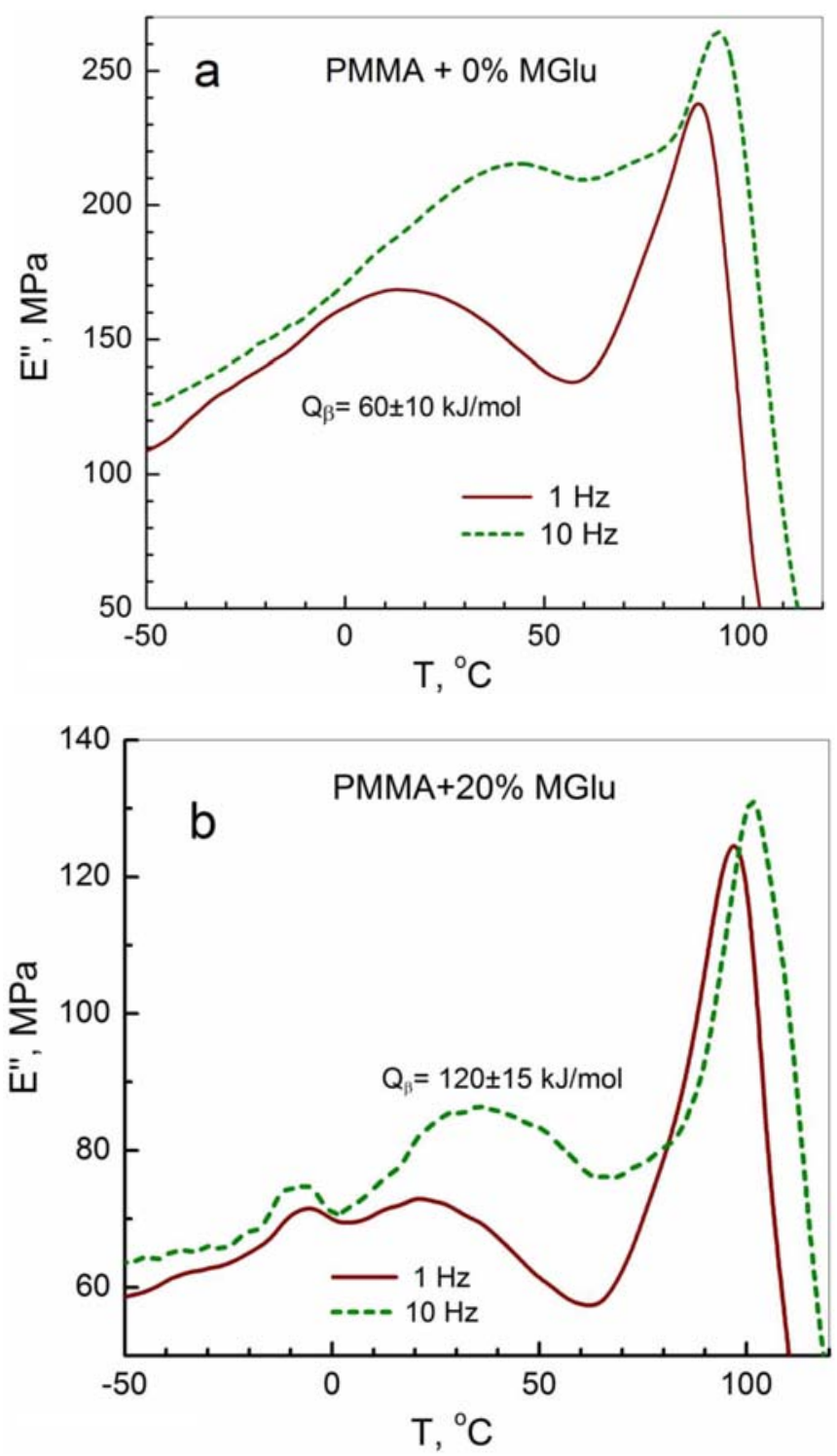

Figure 6. DMA: loss modulus $E^{\prime \prime}$ versus temperature dependencies obtained at 1 and $10 \mathrm{~Hz}$ for (a) PMMA and (b) MMA copolymer with 20wt.\% MGlu. The calculated activation energies of $\beta$-relaxation are indicated. 
VLADIMIR BERSHTEIN et al.
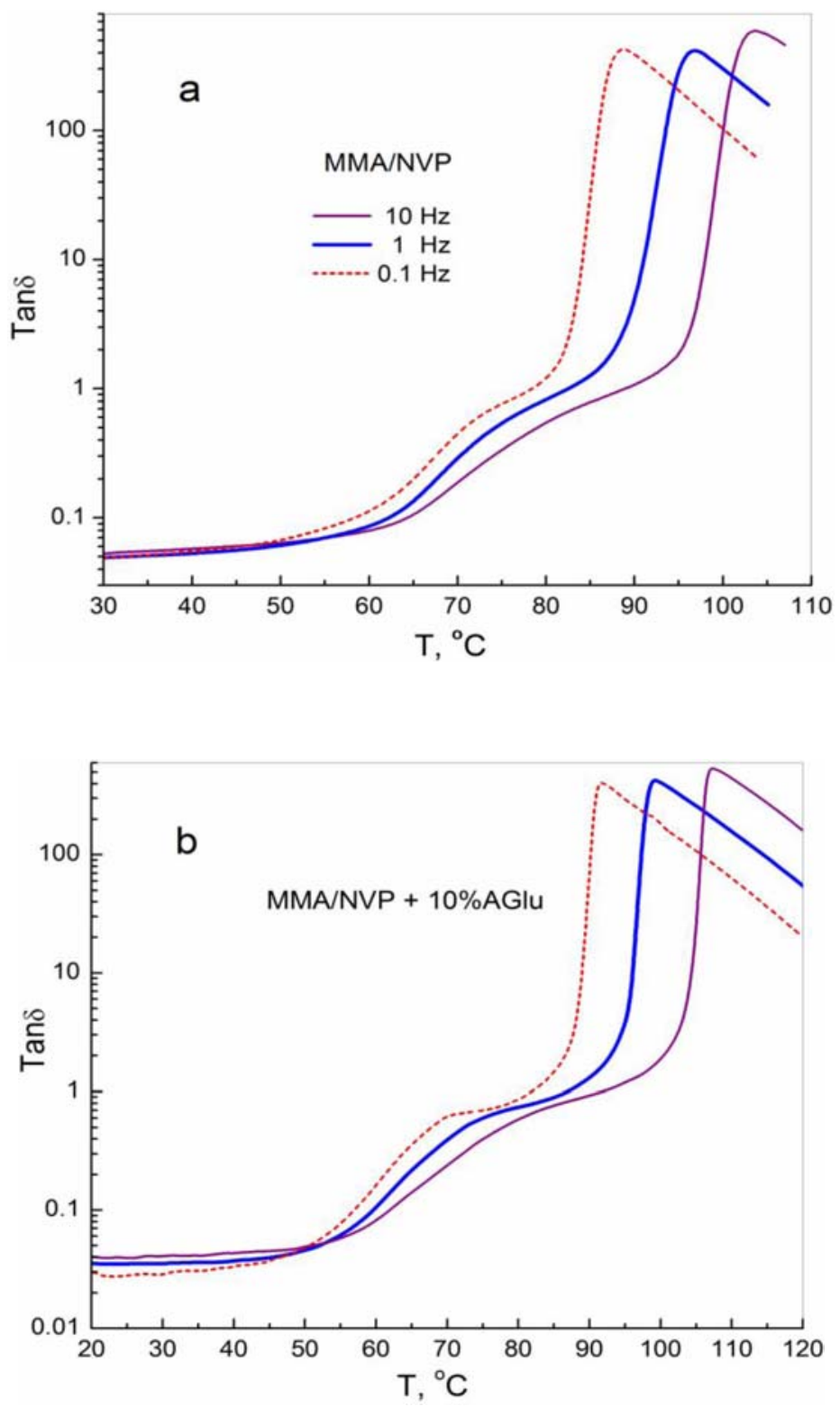


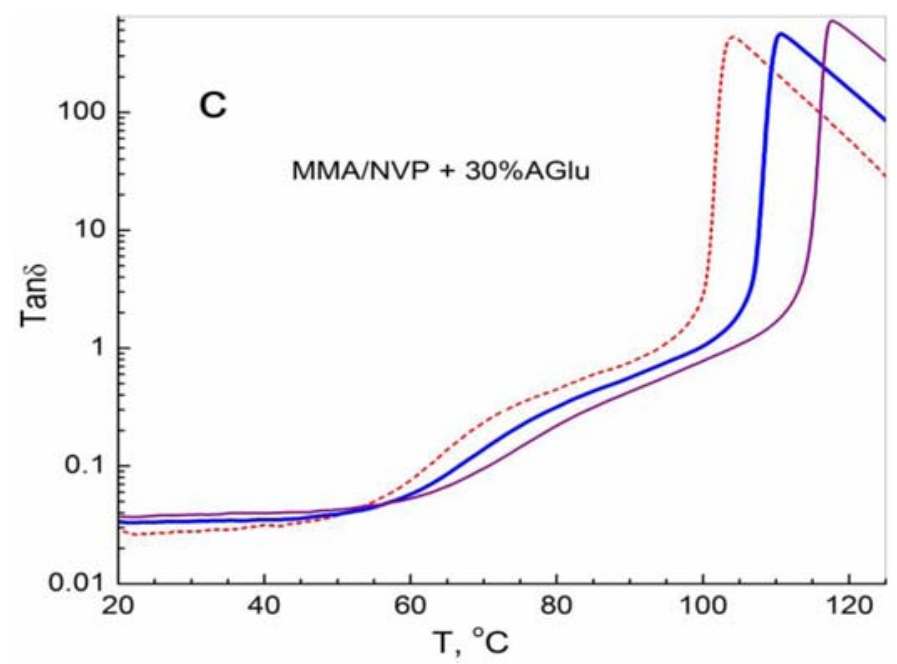

Figure 7. DMA: mechanical loss factor $\tan \delta$ versus temperature dependencies obtained at $0.1,1$, and $10 \mathrm{~Hz}$ for (a) MMA/NVP copolymer, (b) its hybrid with 10wt.\% AGlu, and (c) its hybrid with 30wt.\% AGlu.

\subsection{Thermogravimetric analysis}

Figures 8 and 9 display the comparative TGA data obtained for PMMA, MMA/NVP copolymer, polymerized MGlu and AGlu, and for a few indicated hybrids. One can see rather different thermal behaviour of these materials depending both on their compositions and the temperature regions.

PMMA is known by its ability to depolymerization starting from the moderate temperatures of about $130^{\circ} \mathrm{C}-150^{\circ} \mathrm{C}$ and more intensely at $170^{\circ} \mathrm{C}-200^{\circ} \mathrm{C}$; that may be discerned from Figure 8. Incorporating MGlu units into PMMA chains exerted some positive effect on thermal stability of PMMA at $130^{\circ} \mathrm{C}-150^{\circ} \mathrm{C}$ but decreased it at $170^{\circ} \mathrm{C}-200^{\circ} \mathrm{C}$ (Figure $8(\mathrm{a})$ ). On the contrary, incorporating AGlu units in PMMA resulted in enhancing its thermal stability up to $\sim 240^{\circ} \mathrm{C}$ (Figure $8(\mathrm{~b})$ ). One can see also from Figure 8 that polymerized MGlu and AGlu are characterized with very intense thermal destruction in the temperature region of $260^{\circ} \mathrm{C}-280^{\circ} \mathrm{C}$, whereas PMMA and its hybrids manifest the maxima at TGA curves at about $300^{\circ} \mathrm{C}$ and $350^{\circ} \mathrm{C}$. 
Figure 9 shows the influence of incorporating AGlu units on MMA/NVP copolymer thermal stability. One can see that introducing 20-30wt.\% AGlu into this copolymer substantially increases its thermal stability at $100^{\circ} \mathrm{C}-200^{\circ} \mathrm{C}$ decreasing it only at very high temperatures (over $300^{\circ} \mathrm{C}$ ). 

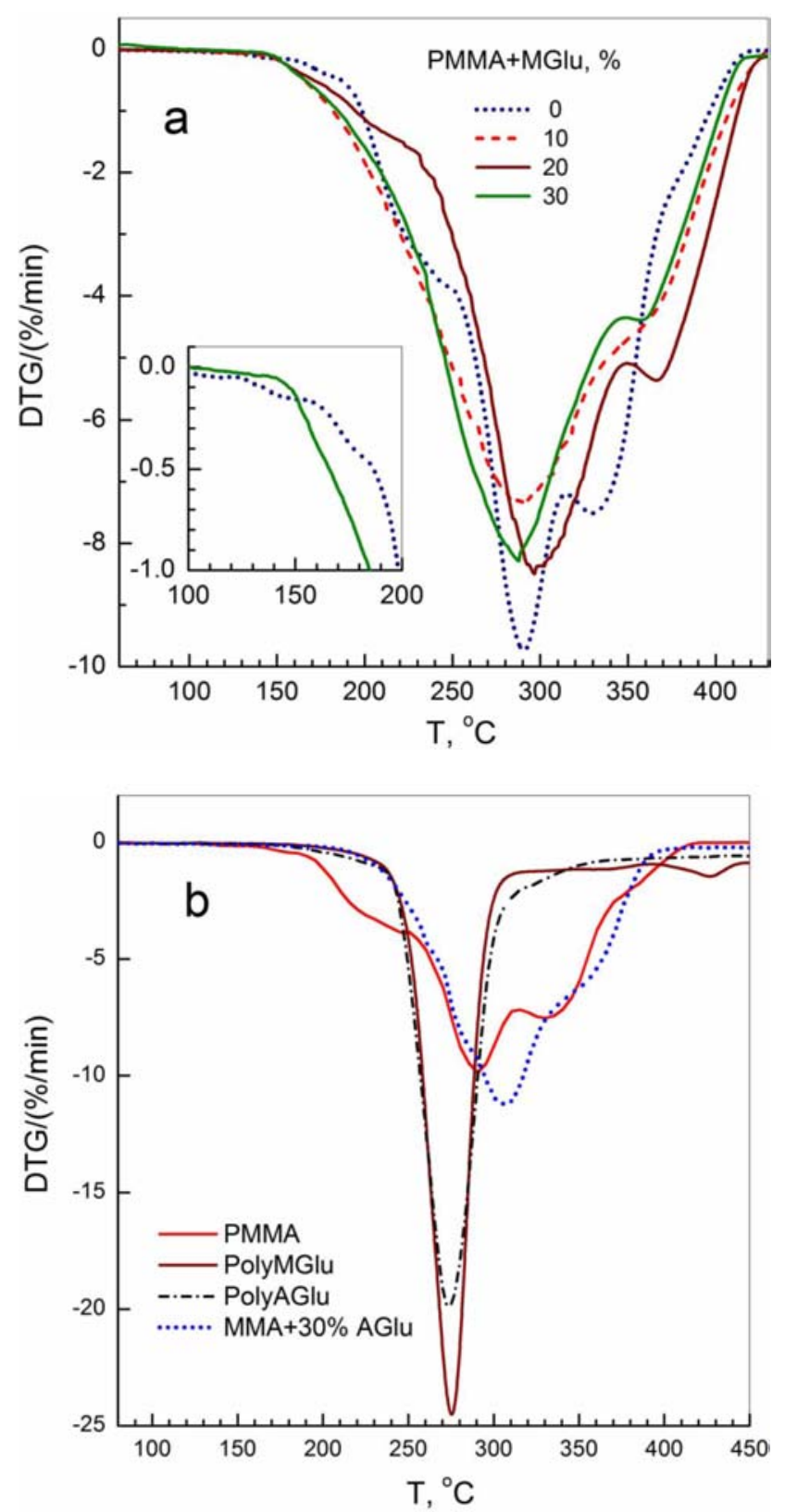

Figure 8. TGA: DTG curves obtained for (a) PMMA and MMA hybrids (copolymers) with 10, 20, and 30wt.\% MGlu, (b) PMMA, polyMGlu, polyAGlu and MMA hybrid (copolymer) with 30wt.\% AGlu. 


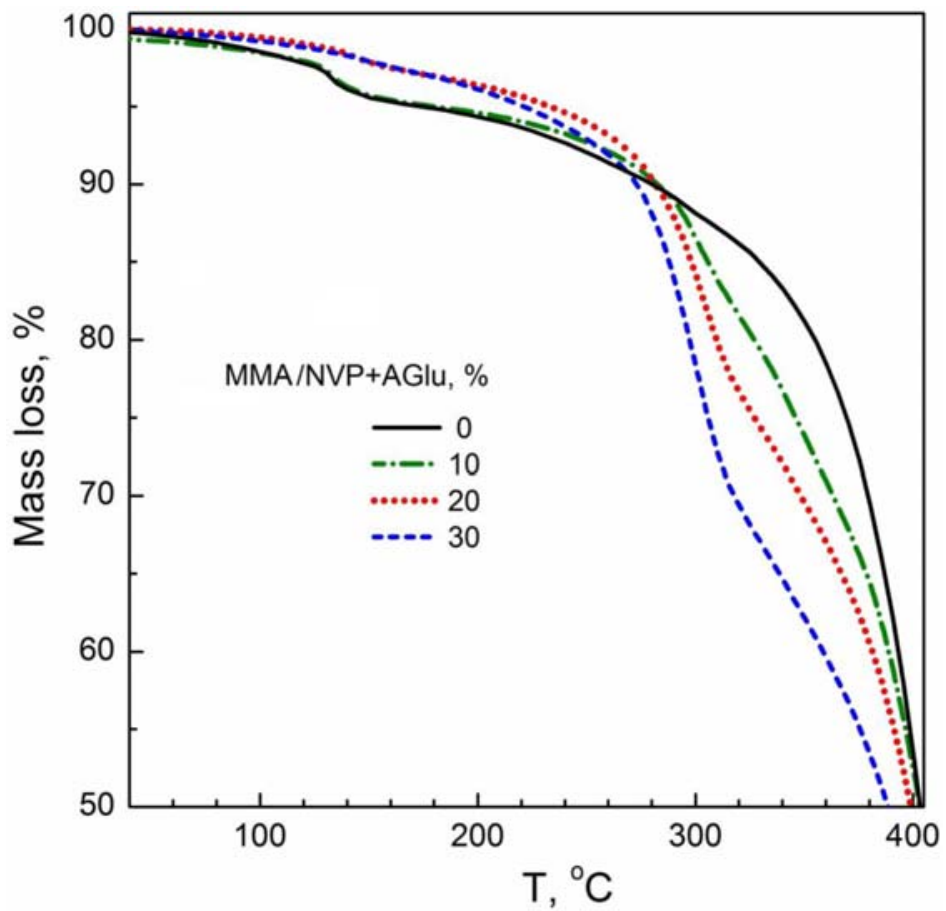

Figure 9. TGA data obtained for MMA/NVP copolymer and its hybrids with 10, 20, and 30wt.\% AGlu.

\subsection{Biodegradability}

Figures 10(a) and (b) show the results of estimating the comparative capability of the materials studied to biodegradation. One can see that the latter depends on both the type of carbochain polymer and the modifier content, AGlu or MGlu. It should be noted that the effects were qualitatively identical after incorporating MGlu or AGlu into chains. Different capability to biodegradation of neat PMMA and MMA/NVP copolymer is observed. For PMMA biodegradability is absent at all. Meantime, the larger water sorption of MMA/NVP copolymer resulted to its notable biodegradation. It assumes that water sorption is the necessary condition for manifesting biodegradadility of polymer systems. Only negligibly small effect of increasing biodegradability was registered recently [11] after modifying 
PMMA, for MMA-methacrylated galactose copolymer. The same result is observed also for PMMA/AGlu systems (Figure 10(a)). One can see, however, that incorporating, e.g., 10\% MGlu into MMA/NVP copolymer provides the essential increase in biodegradability of the hybrid regarding the initial carbochain copolymer (Figure 10(b)). 

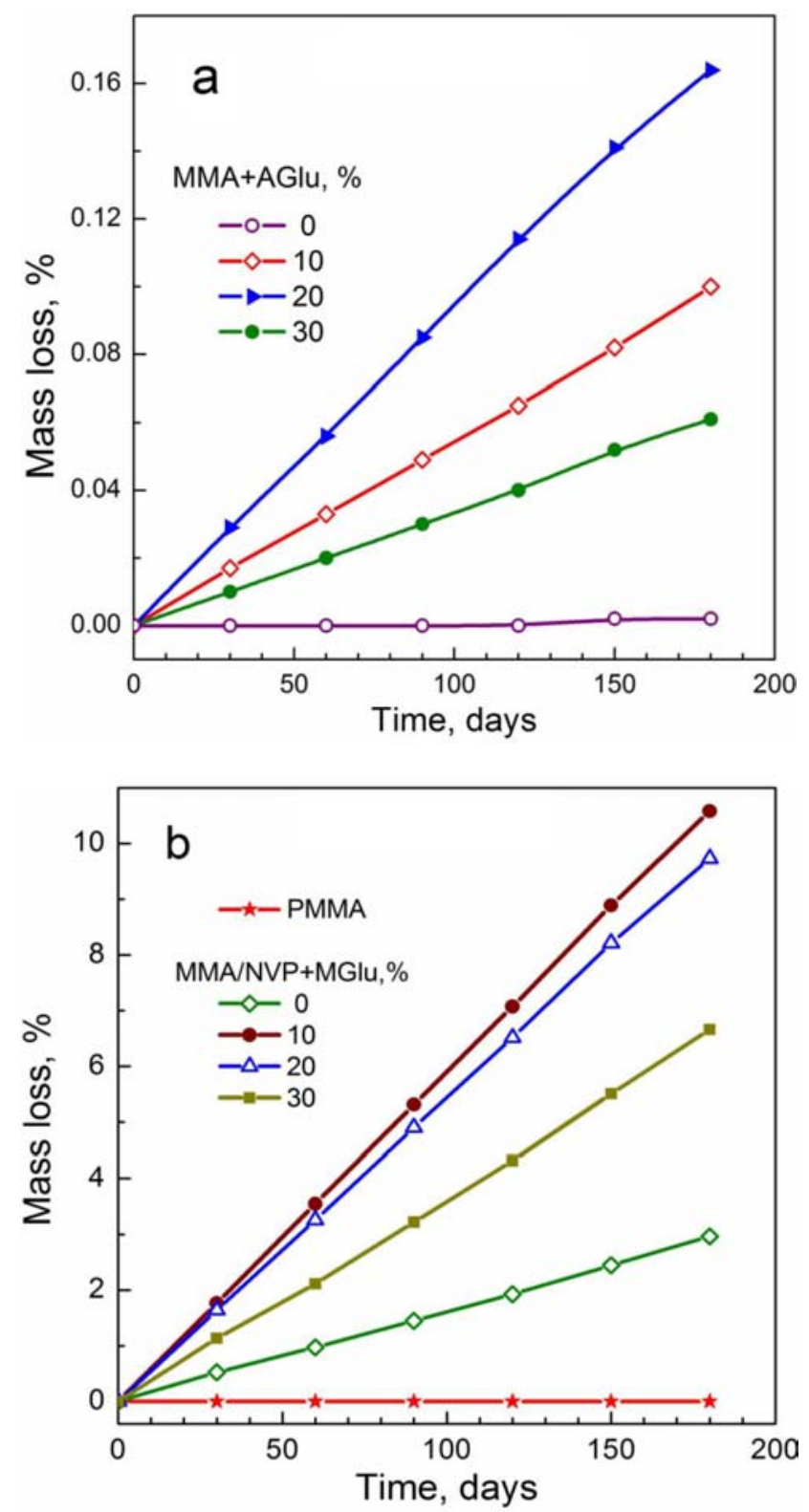

Figure 10. Biodegradability tests: mass loss versus time of exposure in soil for (a) PMMA and MMA copolymer with 10, 20, and 30wt.\% AGlu, and (b) PMMA, MMA/NVP copolymer and its hybrids (copolymers) with 10, 20, and 30wt.\% MGlu. 


\section{Conclusion}

The synthesized novel monomers- glucose derivatives, such as methacrylated and acrylated ones (MGlu, AGlu), were embedded, via copolymerization, into carbochain polymers, PMMA and MMA/NVP copolymer. Analysis of the hybrids obtained indicated the essential changes in polymers' properties after their modification. For instance, introducing MGlu additive into MMA/NVP copolymer chains may result to increasing $T_{\mathrm{g}}$ from $97^{\circ} \mathrm{C}$ to $126^{\circ} \mathrm{C}$, dynamic modulus $E^{\prime}$ from 1.3GPa to 2.0GPa, and to generation of substantial biodegradability of this carbochain polymer. Embedding AGlu into both polymers provided increasing thermal stability in the temperature region from $\sim 150^{\circ} \mathrm{C}$ to $240^{\circ} \mathrm{C}$. The essential biodegradability rise became possible only for MMA/NVP copolymer, owing to increased water absorption, since this effect was negligibly small for PMMA. The effect of some suppression of molecular mobility in these hybrids ("constraining dynamics") manifested itself also in the broad temperature region of sub- $T_{\mathrm{g}}$ relaxations. The further studies in this rather slightly investigated field of the hybridzation of synthetic polymers with natural products, e.g., such as monosaccharides, are of interest for different applications.

\section{Acknowledgement}

This research was supported in part by the People Programme (Marie Curie Actions) of the EU 7th Framework Programme FP7/2007-2013 under PIRSES-GA-2013-612484 grant.

\section{References}

[1] D. R. Lu, C. M. Xiao and S. J. Xu, Starch-based completely biodegradable polymer materials, eXPRESS Polym. Lett. 3(6) (2009), 366-375.

DOI: https://doi.org/10.3144/expresspolymlett.2009.46

[2] Y. Baimark, M. Srisa-ard and P. Srihanam, Morphology and thermal stability of silk fibroin/starch blended microparticles, eXPRESS Polym. Lett. 4(12) (2010), 781-789.

DOI: https://doi.org/10.3144/expresspolymlett.2010.94 
[3] J. A. Ratto, P. J. Stenhouse, M. Auerbach, J. Mitchell and R. Farrell, Processing, performance and biodegradability of a thermoplastic aliphatic polyester/starch system, Polymer 40(24) (1999), 6777-6788.

DOI: https://doi.org/10.1016/S0032-3861(99)00014-2

[4] L. F. Boesel, J. F. Mano and R. L. Reis, Optimization of the formulation and mechanical properties of starch based partially degradable bone cements, J. Mater. Sci.: Mater. Medicine 15(1) (2004), 73-83.

DOI: https://doi.org/10.1023/B:JMSM.0000010100.07715.eb

[5] A. V. Reis, M. R. Guilherme, T. A. Moia, L. H. C. Mattoso, E. C. Muniz and E. B. Tambourgi, Synthesis and characterization of a starch-modified hydrogel as potential carrier for drug delivery system, J. Polym. Sci. Part A: Polym. Chem. 46(7) (2008), 2567-2574.

$$
\text { DOI: http://dx.doi.org/10.1002/pola.22588 }
$$

[6] D. Wang, Z.-Q. Song and S.-B. Shang, Characterization and biodegradability of amphoteric superabsorbent polymers, J. Appl. Polym. Sci. 107(6) (2008), 4116-4120.

DOI: http://dx.doi.org/10.1002/app.27639

[7] S.-R. Vilches, C. Severac, C. Thibaut, L. Laplatine, C. Vieu, J. Fitremann, A.-F. Mingotaud, P. Martinoty and D. Collin, Nanostructuration of soft hydrogels: Synthesis and characterization of saccharidic methacrylate gels, Colloid Polym. Sci. 289(13) (2011), 1437-1449.

DOI: https://doi.org/10.1007/s00396-011-2465-1

[8] X. Way, Y. Gao, H. Zhao, X.-Q. Liu, Z. Wang, A. Qin, Q. Hu, J. Z. Sun and B. Z. Tang, Monosaccharide-functionalized poly(phenylacetylenes): in situ polymerization, hybridization with multi-walled carbon nanotubes, and application in the reinforcement of chitosan rods, Polym. Chem. 5(21) (2014), 6216-6224.

\section{DOI: http://dx.doi.org/10.1039/C4PY00809J}

[9] K. K. L. Cheuk, J. W. Y. Lam, B. S. Li, Y. Xie and B. Z. Tang, Decorating conjugated polymer chains with naturally occurring molecules: Synthesis, solvatochromism chain helicity and biological activity of sugar-containing poly(phenylacetylene)s, Macromolecules 40(8) (2007), 2633-2642.

DOI: http://dx.doi.org/10.1021/ma062629d

[10] S. Mallakpour, A. Abdolmaleki and M. Rostani, Glucose-functionalized MWCNTs dispersing and hosting nanotubes for poly(amide-imide) bionanocomposites containing N,N'-(pyromellitoyl)-bis-S-valine, J. Polym. Res. 22 (2015), 1-9.

DOI: https://doi.org/10.1007/s10965-015-0690-x

[11] P. N. Yakushev, V. A. Bershtein, I. Bukowska-Śluz, M. Sobiesiak and B. Gawdzik, Methacrylated monosaccharides as the modifiers for carbochain polymers: Synthesis, mechanical/thermal properties and biodegradability of hybrids, TOP-2016 Conference, Italy, June 2016, AIP Conf. Proc. 1736, 020045 (2016), 4. 
[12] A. I. Vogel, Preparatyka organiczna, WNT, Warszawa, 2006.

[13] V. A. Bershtein and V. M. Egorov, Differential Scanning Calorimetry of Polymers, Physics Chemistry, Analysis, Technology, Ellis Horwood, New York, 1994.

[14] V. A. Bershtein and P. N. Yakushev, Laser-interferometric creep rate spectroscopy, Adv. Polym. Sci. 230 (2010), 73-219. 